\title{
CRESCIMENTO INICIAL DE PORTA-ENXERTO (LIMÃO CRAVO) SUBMETIDO À EMBEBIÇÃO E PULVERIZAÇÃO FOLIAR COM STIMULATE ${ }^{\circledR}$
}

\author{
Cleiton de Almeida Gonçalves ${ }^{1}$, Elvis Lima Vieira ${ }^{2}$, Carlos Alberto da Silva Ledo ${ }^{3}$
}

\section{RESUMO:}

O objetivo do estudo foi avaliar a influência do biorregulador vegetal, Stimulate, via embebição de sementes, pulverização foliar no crescimento inicial de plântulas e no desenvolvimento radicular de limão cravo (Citrus limonia Osbeck) sob condições de rizotron. O experimento foi conduzido em casa de vegetação em duas etapas: 1)plantio em sacos plásticos de polietileno preto (de $15 \mathrm{~cm}$ de largura x $20 \mathrm{~cm}$ de comprimento0; e 2) em condições de rizotron, na qual foram utilizadas sementes de limão cravo e o biorregulador Stimulate, nas concentrações, 0,0 (controle); 2,5; 5,0; 7,5; 10,0; 12,5; 15,0 mL de Stimulate L ${ }^{1}$ de solução aquosa para embebição de sementes durante uma hora. E as concentrações 0,0 (controle); 2,5; 3,$75 ; 5,0 ; 6,25 ; 7,5 ; 8,75 \mathrm{~mL}$ de Stimulate $\mathrm{L}^{-1}$, via pulverização foliar no crescimento inicial de plântulas nas duas etapas. O delineamento experimental foi inteiramente casualizado com sete tratamentos e quatro repetições, sendo utilizadas cinco plantas por parcela. Aos 16 dias após a semeadura (DAS) realizou-se o desbaste deixando uma planta por saco e aos 150 DAS, as plantas foram submetidas a sete pulverizações semanais com as soluções de Stimulate. Aos 210 DAS registraram-se: comprimento da raiz, comprimento de caule, número de folhas, massa seca de raiz, massa seca de folha, massa seca de caule e massa seca total das plantas e área foliar. Em condições de rizotron fez-se o desbaste aos 16 DAS deixando uma planta por rizotron, registrando-se as variáveis aos 82 DAS: velocidade de crescimento da raiz principal, comprimento total das raízes e taxa de crescimento diário da raiz. A pré-embebição das sementes de limão cravo com o biorregulador em condições de rizotron demonstrou um aumento no comprimento total da raiz e da taxa de comprimento diário da raiz principal. O Stimulate, via pulverização foliar, aumentou significativamente o número de folhas, o comprimento da haste e o comprimento total, o incremento na massa seca de folha e a área foliar das plantas de limão cravo.

Palavras-chave: Citrus limonia Osbeck, biorregulador vegetal, produção de mudas e desenvolvimento.

\section{INITIAL GROWTH OF GRAVE HOLDER (LEMON) SUBMITTED TO FLOATING AND FOLIAR SPRAYING WITH STIMULATE ${ }^{\circledR}$}

\begin{abstract}
:
The objective of this study was to evaluate the influence of the plant bioregulator, Stimulate, via seed imbibition and foliar spraying on initial seedling growth and root development of lemon (Citrus limonia Osbeck) under rizotron conditions. The experiment was conducted in a greenhouse in two stages: 1) planting in plastic bags of black polyethylene (15 cm wide x $20 \mathrm{~cm}$ long); 2) and under rizotron conditions, in which

\footnotetext{
${ }^{1}$ Graduação em Agronomia, Mestre em Ciências Agrárias- UFRB; Fundação de Apoio a Agricultura Familiar do Semiárido da Bahia- FATRES, Valente-BA; cleitonagr@ hotmail.com

${ }^{2}$ Graduação em Agronomia, Doutorado em Fitotecnia- USP; Centro de Ciências Agrárias; Ambientais e Biológicas-UFRB; Cruz das Almas-BA; elvieira@ufrb.edu.br

${ }^{3}$ Graduação em Agronomia, Doutorado em Genética e Melhoramento de Plantas- UFV; Embrapa Mandioca e Fruticultura, Cruz das Almas-BA; carlos.ledo@embrapa.br
} 
lemon seeds and the bioregulator Stimulate were used, in concentrations, 0.0 (control); $2.5 ; 5.0 ; 7.5 ; 10.0$; $12.5 ; 15.0 \mathrm{~mL}$ of Stimulate L-1 aqueous solution for seed imbibition soaking for 1 hour. And the concentrations 0,0 (control); $2.5 ; 3.75 ; 5.0 ; 6.25 ; 7.5 ; 8.75 \mathrm{~mL}$ of Stimulate L-1, via foliar spraying on initial seedling growth in the two stages. The experimental design was completely randomized with seven treatments and four replicates, using five plants per plot. At 16 days after sowing (DAS), thinning was done, leaving one plant per plastic bag. At 150 DAS, the plants were submitted to seven weekly spray with Stimulate solutions. At 210 DAS the following were recorded: root length, stem length, leaf number, root dry mass, leaf dry mass, dry stem mass and total dry mass of the plants and leaf area. Under rhizotron conditions, thinning was done at 16 DAS, leaving one plant per rizotron with the following variables recorded at 82 DAS: main root growth rate, total root length, daily root growth rate. Pre-soaking of clove lemon seeds with the bioregulator under rizotron conditions demonstrated an increase in total root length and daily root length rate of the main root. The Stimulate via leaf spraying significantly increased the number of leaves, stem length and total length, increment in leaf dry mass and leaf area of the lemon plants.

Keywords: Citrus limonia Osbeck, bioregulators vegetable, seedling production and development. 


\section{INTRODUÇÃO}

$\mathrm{Na}$ fruticultura, a citricultura é a atividade que mais se destaca mundialmente. O Brasil se destaca nesse cenário porque é o maior produtor de laranja (FAO, 2017). E conjuntura exige estratégias a médio e longo prazo para solução de problemas decorrentes de ordem econômica, científica e tecnológica ascendentes e constantes (IAC, 2016). A muda é um dos fatores fundamentais para o desenvolvimento da citricultura, por constituir a base de formação dos pomares influenciando diretamente na vida útil do pomar (Rezende et al., 2010). Sendo assim, para a produção de mudas cítricas certificadas, além de seguir as Instrução Normativa $\mathrm{N}^{\mathrm{o}} 48$, de 24 de setembro de 2013, que estabelece as normas de produção e de comercialização de material de propagação de Citrus spp., Fortunella spp., Poncirus spp. e de seus híbridos, devem ser levados em consideração diversos outros fatores, principalmente os relacionados à qualidade de sementes, semeadura, germinação e emergência dos porta-enxertos, que são conduzidos até a fase de enxertia, etapa que chega a ocupar cerca de $60 \%$ do tempo total de produção da muda (BRASIL, 2013; Rodrigues et al., 2015).

A aplicação foliar de produtos químicos visando provocar alterações morfológicas e fisiológicas em cítricos têm sido pouco utilizadas em nossas condições. Com a evolução da citricultura brasileira, a aplicação desses produtos químicos pode ser interessante, uma vez que podem possibilitar a atenuação de problemas existentes no sistema de produção da cultura ou mesmo aumentar quantitativamente e melhorar a qualidade da produção (Castro et al., 1996). Neste contexto, a auxina tem sido utilizada no enraizamento de estacas de citros, como o AIB (ácido indolbutírico); na fixação de frutos, como o 2,4-D (ácido 2,4diclofenoxiacético) ou no releio de frutos como ANA (ácido naftaleno acético).
A pulverização invernal de cítricos com giberelina e citocinina (benziladenina) induziu a quebra de dormência de gemas e a emergência de brotações. Ambas as substâncias aumentaram o crescimento, tanto de folhas como de frutos, pois alteraram a produção e alocação de fotoassimilados durante o desenvolvimento dos órgãos reprodutivos (Agusti e Almela, 1991).

O Stimulate é um biorregulador que contém reguladores vegetais (ácido índolbutírico: auxina0,005\%; cinetina: citocinina- $0,009 \%$ e ácido giberélico: giberelina-0,005\%). Esse produto químico incrementa o crescimento e o desenvolvimento vegetal estimulando a divisão celular, a diferenciação e o alongamento das células, também aumenta a absorção e a utilização dos nutrientes e é especialmente eficiente quando aplicado com fertilizantes foliares, sendo também compatível com defensivos (Castro et al., 1996; Natale et al., 2004; Souza et al., 2013; Amaral et al., 2017). Souza et al. (2013), com a aplicação de bioestimulante, na forma do produto comercial Stimulate, na dose de $6 \mathrm{~mL} \mathrm{~kg}^{-1}$ em sementes do porta-enxerto cítrico tangerineira 'Cleópatra', obtiveram resultados positivos com incrementos no diâmetro do caule, número de folhas e área foliar, indicando o bioestimulante como promissor para a diminuição no tempo de formação desse portaenxerto.

Visando à formação de porta-enxerto de limão cravo, o presente trabalho teve como objetivo, avaliar a influência do biorregulador vegetal via embebição de sementes e pulverização foliar no crescimento inicial de plantas de limão cravo e desenvolvimento radicular em condições de rizotron.

\section{MATERIAL E MÉTODOS}

$\mathrm{O}$ ensaio foi conduzido em casa de vegetação, na Universidade Federal do Recôncavo da Bahia, no município de Cruz das Almas-BA. 
Foram utilizadas sementes de limão cravo sem mucilagem, tratadas com Orthocide ${ }^{\circledR} 500,5 \mathrm{~g} \mathrm{~L}^{-1}$ (ingrediente ativo Captana $500 \mathrm{~g} \mathrm{Kg}^{-1}$ ) durante cinco minutos e depois posta para secagem à sombra durante três dias. O experimento foi conduzido em duas etapas: na primeira foram feitas as semeaduras em sacos plásticos de polietileno preto de capacidade de $2 \mathrm{~kg}$ com areia lavada e terra vegetal na proporção (1:1). Utilizaram-se quatro sementes pré-embebidas com biorregulador vegetal da Stoller do Brasil, Stimulate ${ }^{\circledR}(0,009 \%$ de cinetina, $0,005 \%$ de ácido indolbutírico e $0,005 \%$ de ácido giberélico) nas concentrações 0,0 (controle); 2,5; 3,75; 5,0; 6,$25 ; 7,5 ; 8,75 \mathrm{~mL}$ de Stimulate ${ }^{\circledR} \mathrm{L}^{-1}$, o pH da calda foi ajustado para 5,0. Aos 16 dias após semeadura (DAS) foi realizado desbaste deixando-se uma planta por saco plástico, aos 30 DAS iniciou-se a pulverização via foliar do biorregulador, realizaram cinco pulverizações nas mesmas dosagens da préembebição sem adição de espalhante adesivo na calda, com intervalos a cada 30 dias, as variáveis analisadas foram: altura das plantas (cm), comprimento da raiz principal $(\mathrm{cm})$, número de folhas (contagem), massa seca das partes constituintes ( $\mathrm{g}$ ) e área foliar (estimada pela fórmula $\mathrm{AF}=\mathrm{PF} \times \mathrm{AD} / \mathrm{PD}$, onde AF é a área foliar estimada; $\mathrm{PF}$ é a massa fresca da folha; $\mathrm{AD}$ é a área conhecida do disco retirado da folha e PD é a massa fresca do disco), as determinações foram realizadas aos 210 DAS.

Na segunda etapa, em condições de rizotron, utilizou-se o biorregulador, via pré-embebição durante uma hora, nas concentrações 0,0 (controle); 2,$5 ; 5,0 ; 7,5 ; 10,0 ; 12,5 ; 15,0 \mathrm{~mL}$ de Stimulate ${ }^{\circledR} \mathrm{L}^{-1}$ de solução aquosa, depois foi realizada a semeadura, com quatro sementes por rizotron. Aos 22 dias após a semeadura (DAS) foi realizado desbaste, deixando apenas uma planta por rizotron, início das avaliações do crescimento de raiz $\left(\mathrm{cm} \mathrm{dia}{ }^{-1}\right)$, período em que também foram realizadas as pulverizações foliares nas mesmas dosagens da pré-embebição, com aplicação a cada sete dias até a raiz principal tocar no fundo do rizotron, com término do experimento aos 82 DAS.
Os rizotrons foram constituídos de PVC de polietileno protegido, vidro transparente $(4,0 \mathrm{~mm})$, canaletas de alumínio e madeira, com volume de $5,850 \mathrm{~cm}^{3}$, de formato retangular com $50,0 \mathrm{~cm} \mathrm{de}$ altura, 39,0 cm de largura por 3,0 $\mathrm{cm}$ de espessura. Preenchidos com o solo Latossolo Amarelo, peneirado e colocados em casa de vegetação sobre mesas de madeira e levemente inclinados, formando um ângulo de $25^{\circ}$ com a vertical (Glinski et al., 1993) para facilitar o geotropismo positivo das raízes das plantas. O final do experimento foi determinado quando a raiz principal de qualquer um dos tratamentos atingisse o fundo do rizotron. Os parâmetros avaliados foram: número de folhas (contagem), altura da planta $(\mathrm{cm})$, velocidade de crescimento da raiz principal $\left(\mathrm{cm} \mathrm{dia}{ }^{-1}\right.$ ), taxa de crescimento diário (valor médio do crescimento diário dividido pelo número de dias) e comprimento total das raízes $(\mathrm{cm})$. $\mathrm{O}$ delineamento foi inteiramente casualizado com tratamentos compostos de quarto repetições de cinco plantas cada uma para experimento em sacos plásticos. Em condições de rizotron foram sete tratamentos, quatro repetições (quatro rizotrons) por tratamento, contendo uma planta cada rizotron. Todas as variáveis foram submetidas à análise de variância e para as médias dos tratamentos foram ajustadas equações de regressão polinomial. Utilizou-se o programa estatístico SISVAR (Ferreira, 2011) para realização das análises estatísticas.

\section{RESULTADOS E DISCUSSÃO}

\section{Ação do Stimulate no crescimento inicial de plantas cítricas}

A análise de variância apresentada na (Tabela 1) revelou significância para as variáveis: número de folhas, comprimento de haste, comprimento total da planta, massa seca de folha, massa seca de haste e área foliar das plantas aos 210 dias após a semeadura. Com isso, notou-se a influência das concentrações do produto positivamente utilizadas, corroborando com diversos 
autores da literatura e, principalmente, com a composição do Stimulate, quando utilizado nas plantas como biorregulador composto por combinação de reguladores vegetais e quando utilizado em conjunto para garantir um adequado equilíbrio hormonal estimulando a formação das plantas eficientemente proporcional às suas dosagens.

Nesse sentido, Tecchio et al. (2015) observaram que a concentração de $200 \mathrm{~mL} \mathrm{~L}^{-1}$ de Stimulate via pulverização foliar promoveu aumento na altura da planta, no número de folhas, no comprimento da raiz e no diâmetro da copa das mudas de um tipo de citrus ornamental (Kunquat 'Nagami'). Echer et al. (2006), em ensaio com maracujá amarelo, observaram que a aplicação de Stimulate via sementes proporcionou incremento na área foliar, acúmulo de massa seca e sistema radicular bem desenvolvido, promovendo maior equilíbrio entre o sistema radicular e a parte aérea, o que pode favorecer o estabelecimento da muda no campo. Santos e Vieira (2005), analisando a aplicação do biorregulador Stimulate em sementes de algodão, observaram que esse procedimento originou plântulas mais vigorosas, com maior comprimento e massa seca. Observaram também um incremento da área foliar e na altura quando utilizaram as concentrações entre 9,8 e $14 \mathrm{~mL}$ de Stimulate $0,5 \mathrm{Kg}^{-1}$ de sementes.

Derivando a equação de regressão $\hat{Y}=0$, $7672 x+12,13$, que apresenta boa qualidade de ajuste, constatada pelo valor do coeficiente de determinação $\left(\mathrm{R}^{2}\right)$ de $84,29 \%$, com crescente número de folhas em função das diferentes doses $\mathrm{o}$ número máximo de 18,8 folhas na maior, um incremento de 6,7 quando comparado com o controle (Figura 1). O comprimento de haste está representado na Figura 2, pela equação linear $\hat{\mathrm{Y}}=$ $1,0672 x+15,496, \quad\left(R^{2}=70,48\right)$, indicando um aumento crescente da variável seguida pelo aumento das concentrações.

A análise de variância revelou diferenças significativas $(\mathrm{P}<0,01)$ e $(\mathrm{P}<0,05)$ no comprimento total, massa seca de haste e área foliar, pelo teste $\mathrm{F}$ para os tratamentos. Apesar do resultado significativo (Tabela 1), não foi possível o ajuste de uma equação de regressão com valores de coeficiente de determinação (R2) altos e com significado biológico. Segundo Banzatto e Kronka (2006), quando determinamos uma equação de regressão é conveniente apresentar o correspondente coeficiente de determinação (R2) que representa, em porcentagem, quanto à variação na resposta é explicada pela regressão em questão.

Tabela 1. Resumo da análise de variância para as variáveis: número de folhas (NF), comprimento da haste $(\mathrm{CH})$, comprimento de raiz (CR), comprimento total (CT), massa seca da folha (MSF) massa seca da haste (MSH), massa seca da raiz (MSR) e área foliar (AF) das plantas de limão cravo, em resposta aos tratamentos via pulverizações com Stimulate ${ }^{\circledR}$ mais controle (água) aos 210 DAS.

\begin{tabular}{|c|c|c|c|c|c|c|c|c|c|}
\hline \multirow[b]{2}{*}{ FV } & \multirow[b]{2}{*}{ GL } & \multicolumn{8}{|c|}{ QUADRADOS MÉDIOS } \\
\hline & & $\begin{array}{c}\text { NF } \\
\text { (und) }\end{array}$ & $\begin{array}{c}\mathrm{CH} \\
(\mathrm{cm})\end{array}$ & $\begin{array}{c}\text { CR } \\
(\mathbf{c m})\end{array}$ & $\begin{array}{c}\text { CT } \\
(\mathrm{cm})\end{array}$ & $\begin{array}{c}\text { MSF } \\
(\mathbf{g})\end{array}$ & $\begin{array}{c}\text { MSH } \\
\text { (g) }\end{array}$ & $\begin{array}{c}\text { MSR } \\
(\mathrm{g})\end{array}$ & $\begin{array}{c}\mathrm{AF} \\
\left(\mathrm{cm}^{2}\right)\end{array}$ \\
\hline Trat & 6 & $31,69 *$ & $73,34 * *$ & $34,98^{\mathrm{ns}}$ & $129,46 * *$ & $0,336 * *$ & $0,144 *:$ & $0,315^{\mathrm{ns}}$ & $129614,10^{*}$ \\
\hline Erro & 28 & 14,17 & 6,87 & 20,61 & 18,10 & 0,056 & 0,012 & 0,035 & 31427,70 \\
\hline $\mathrm{CV}(\%)$ & & 23,78 & 12,70 & 17,99 & 9,27 & 31,27 & 27,60 & 29,68 & 33,29 \\
\hline Média ge & & 15,82 & 20,64 & 25,24 & 45,88 & 0,75 & 0,40 & 0,63 & 532,60 \\
\hline
\end{tabular}

*Significativo a 5\% de probabilidade; ** Significativo a $1 \%$ de probabilidade; ${ }^{\text {ns }}$ não significativo. 


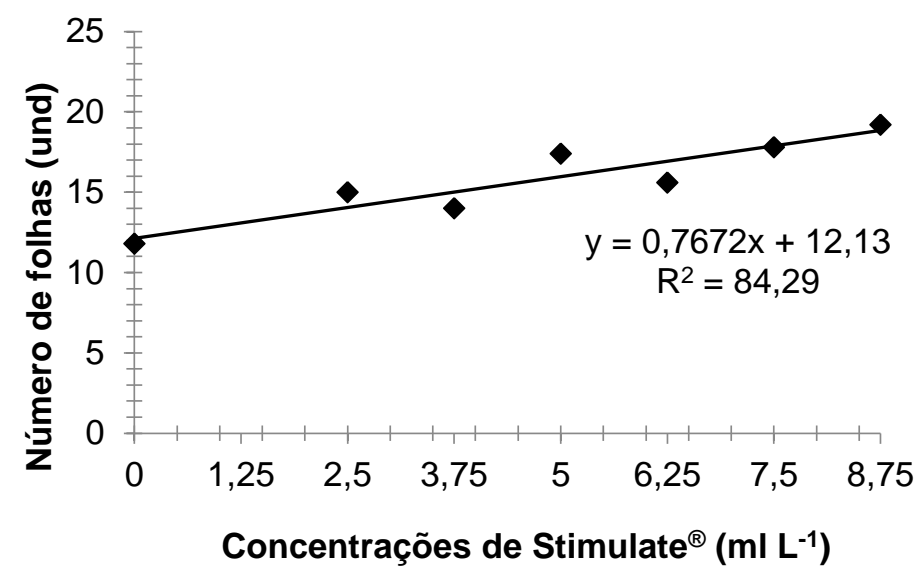

Figura 1. Número de folhas de limão cravo (Citrus limonia Osbeck), submetidas à pulverização foliar com Stimulate ${ }^{\circledR}$.

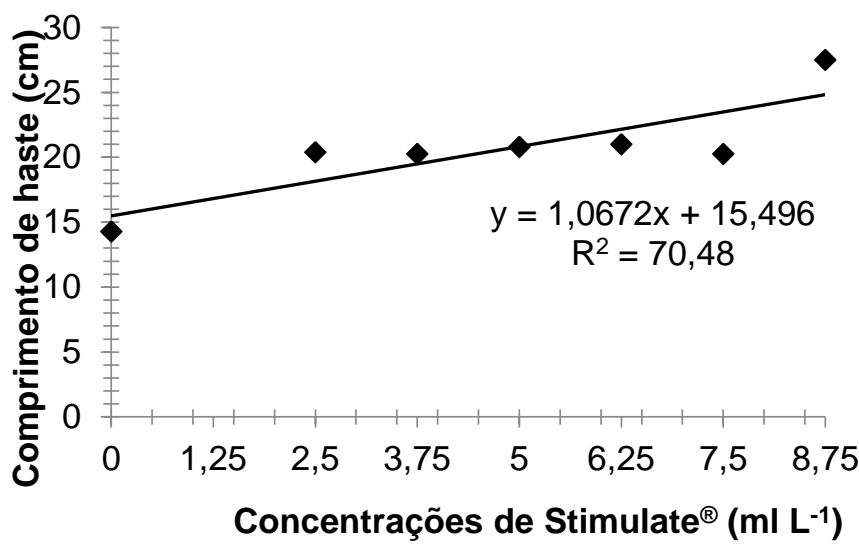

Figura 2. Comprimento de haste de limão cravo (Citrus limonia Osbeck), submetidas à pulverização foliar com Stimulate ${ }^{\circledR}$.

Representada pela equação quadrática $\mathrm{Y}=$ $0,0057 x^{2}+0,0091 x+0,5375$ a massa seca de folha, sofreu o efeito das concentrações de Stimulate diferenciou significativamente $(\mathrm{P}<0,01)$, possuindo significativa qualidade de ajuste com $\mathrm{R}^{2}=50,6 \%$ (Figura 4). Com valores crescentes nas diferentes concentrações ml Stimulate $\mathrm{L}^{-1}$ de solução aquosa, o valor máximo é de $1,05 \mathrm{~g}$, ou seja, um incremento de $48,8 \%$ em relação ao controle. Os resultados demonstram a eficiência e eficácia do Stimulate sobre diversos processos fisiológicos fundamentais das plantas superiores, favorecendo o crescimento inicial das plantas. O Stimulate apresenta um efeito sinergético, em função da presença equilibrada dos reguladores de crescimento (auxina; citocinina e ácido giberélico). Provavelmente, este efeito foi o responsável pelos melhores resultados obtido nas variáveis: altura da planta, massa seca da parte aérea e massa seca da raiz, tendo em vista que esse produto incrementa o crescimento e o desenvolvimento vegetal estimulando a divisão celular, a diferenciação e o alongamento das células, também aumenta a absorção e a utilização dos nutrientes sendo especialmente eficiente quando aplicado com fertilizantes foliares (Castro et al., 1998; Castro e Vieira, 2001). 
Para o comprimento e massa seca da raiz, não foram observados efeitos positivos para limão cravo via pulverização. Na literatura científica, encontram-se trabalhos acerca da utilização de bioestimulantes com efeitos positivos da utilização de produtos compostos de reguladores de crescimento em relação ao desenvolvimento radicular, como observados para as culturas do algodão (Vendruscolo et al., 2015), milho pipoca (Oliveira et al., 2016), soja (Toledo et al., 2015), tamarindo (Dantas et al., 2012), tratadas via semente com Stimulate. Para que ocorram incrementos no sistema radicular capazes de fazer a relação entre a massa de matéria seca das raízes e da parte aérea diferir do controle é necessário que ocorra um efeito sinérgico dos três biorreguladores (ácido giberélico, ácido indolbutírico e cinetina), justificando-se a falta de resposta do limão cravo para essas variáveis, já que foi utilizada pulverização foliar de Stimulate.

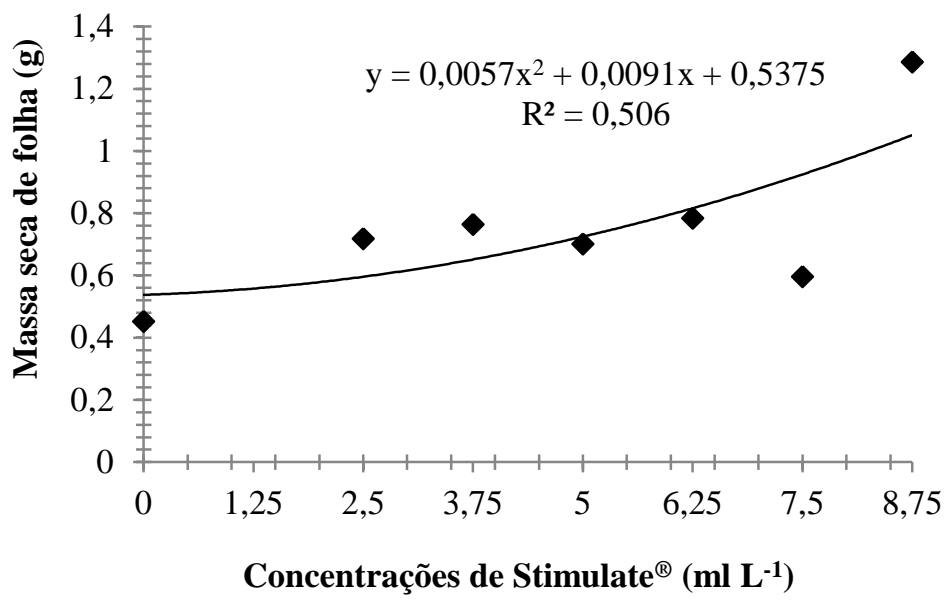

Figura 4. Massa seca de folha em plantas limão cravo (Citrus limonia Osbeck), em resposta a pulverização foliar, com diferentes concentrações de Stimulate ${ }^{\circledR}$.

Ação do Stimulate em porta-enxerto (limão cravo), em condições de rizotron

A análise de variância dos resultados obtidos com o uso do Stimulate via pré-embebição de sementes limão cravo (C. limonia Osbeck), no crescimento radicular de plantas de porta-enxerto em condições de rizotron, revelou efeito altamente significativo $(\mathrm{P}<0,01)$ para as variáveis: comprimento total da raiz e taxa de comprimento radicular diária (Tabela 2). Com relação ao número de folha e comprimento de haste, não houve incremento com a aplicação do regulador via préembebição (Tabela 2).

Santos e Vieira (2005), analisando a aplicação do Stimulate em sementes de algodão, observaram que esse procedimento originou plântulas mais vigorosas, com maior comprimento e massa seca. Observaram também um incremento da área foliar e na altura quando utilizaram as concentrações entre 9,8 e $14,0 \mathrm{~mL}$ de Stimulate 0,5 $\mathrm{Kg}^{-1}$ de sementes. Para comprimento total da raiz (Figura 5), pode ser observado a equação quadrática $\hat{Y}=-0,1581 x^{2}+2,1273 x+31,942$, com coeficiente de determinação $\left(\mathrm{R}^{2}=73,77 \%\right)$. O incremento máximo no comprimento total da raiz foi encontrado na dose de $6,7 \mathrm{~mL}$ de Stimulate $\mathrm{L}^{-1}$ de solução aquosa $(39,0 \mathrm{~cm})$, sendo $18,2 \%$ superior ao controle.

A taxa de comprimento diário da raiz principal da planta de citros em condições de rizotron está representada na (Figura 6), pela equação polinomial do segundo grau $\hat{\mathrm{Y}}=0,0033 \mathrm{x}^{2}+$ $0,0457 x+0,6226$, com coeficiente de determinação $\left(\mathrm{R}^{2}=85,37 \%\right)$, indicando que a dose para se obter 
uma maior taxa é igual a $6,92 \mathrm{ml}$ de Stimulate $\mathrm{L}^{-1} \mathrm{de}$ solução aquosa (ponto de máximo) com uma taxa igual a $0,78 \mathrm{~cm} \mathrm{dia}{ }^{-1}$. Ferrari et al. (2008) observaram que aplicações foliares de Stimulate em plântulas de maracujá-doce proporcionaram curvas da taxa assimilatória líquida e taxa de crescimento relativo elevadas a partir de 76 dias após semeadura com a maior concentração do produto, resultando em plantas com folhas mais espessas, melhor atividade e crescimento.

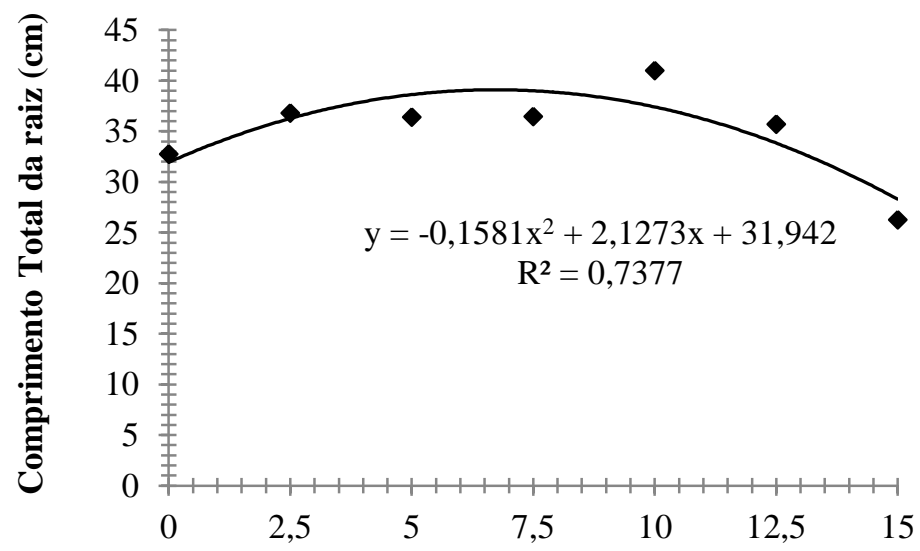

Concentrações de Stimulate ${ }^{\circledR}\left(\mathrm{ml} \mathrm{L}^{-1}\right)$

Figura 5. Comprimento total da raiz de plantas limão cravo (Citrus limonia Osbeck) em condições de rizotron, em resposta a pré-embebição de sementes, com diferentes concentrações de Stimulate ${ }^{\circledR}$.

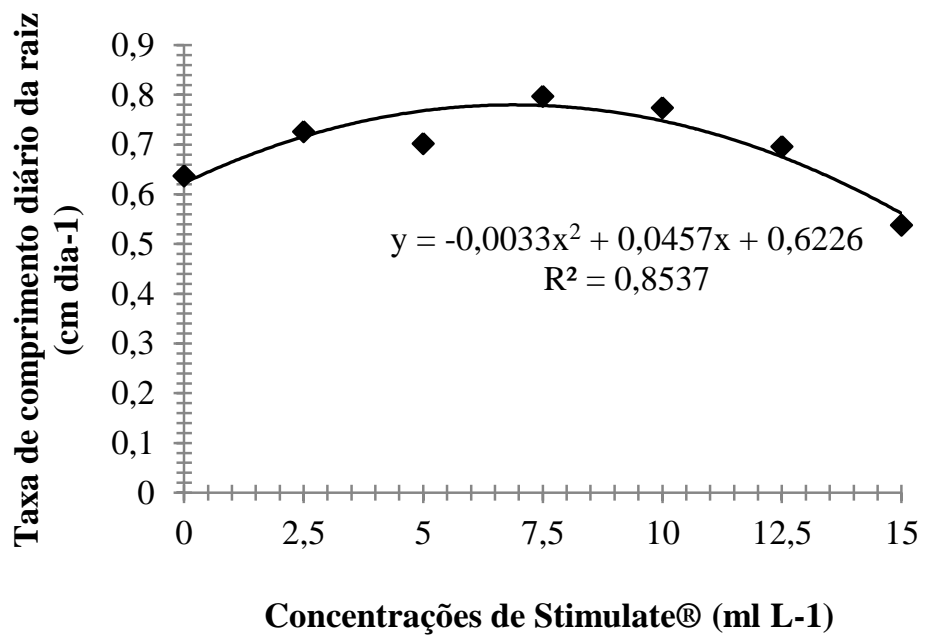

Figura 6. Taxa de comprimento diário da raiz de plantas limão cravo (Citrus limonia Osbeck) em condições de rizotron, em resposta a pré-embebição de sementes, com diferentes concentrações de Stimulate $^{\circledR}$.

\section{CONCLUSÕES}

Os indicadores que subsidiaram a produção deste artigo revelaram que o biorregulador vegetal apresenta influência significativa para o desenvolvimento do limão cravo. Nesse sentido, foi possível constatar três aspectos conclusivos, a saber:

1. A pulverização foliar com Stimulate é eficiente para estimular uma maior produção do 
número de folhas, comprimento de haste, comprimento total da planta e área foliar de citros.

2. As concentrações utilizadas de Stimulate contribuíram para o incremento na massa seca da parte aérea de plantas de limão cravo.
3. A pré-embebição de sementes, promove maior comprimento total da raiz e taxa de comprimento diário da raiz de plantas de limão cravo em condições de rizotron.

Tabela 2. Resumo da análise de variância para as variáveis número de folhas (NF), comprimento da haste $(\mathrm{CH})$, comprimento total de raiz (CTR) e taxa do crescimento diário da raiz (TXCDR) em resposta ao tratamento de sementes de limão cravo via embebição com Stimulate ${ }^{\circledR}$ durante uma hora e água destilada como controle aos 82 DAS.

\begin{tabular}{|c|c|c|c|c|c|}
\hline \multirow[b]{2}{*}{ Fonte de variação } & \multicolumn{5}{|c|}{ Quadrados Médios } \\
\hline & GL & $\begin{array}{c}\text { NF } \\
\text { (und) }\end{array}$ & $\begin{array}{c}\mathrm{CH} \\
(\mathrm{cm})\end{array}$ & $\begin{array}{l}\text { CTR } \\
(\mathrm{cm})\end{array}$ & $\begin{array}{l}\text { TXCDR } \\
(\mathrm{cm} \mathrm{dia}\end{array}$ \\
\hline Tratamento & 6 & $1,51^{\mathrm{ns}}$ & $1,88^{\mathrm{ns}}$ & $69,83 * *$ & $0,024 * *$ \\
\hline Erro & 16 & 1,30 & 1,83 & 17,55 & 0,004 \\
\hline $\mathrm{CV}(\%)$ & & 18,35 & 26,78 & 11,87 & 9,75 \\
\hline Médias & & 6,21 & 5,05 & 35,30 & 0,69 \\
\hline
\end{tabular}

\section{REFERÊNCIAS BIBLIOGRÁFICAS}

Almeida, A.Q. de; Vieira, E.L. (2009). Efeito do Stimulante ${ }^{\circledR}$ na produção de Nicotiana tabacum tipo Brasil-Bahia. Magistra 21 (1):18-22.

Amaral, U. do. (2017). Uso de parafina e bioestimulante em mudas tipo filhote de abacaxizeiro 'Pérola'. Agropecuária Científica no Semiárido 13 (4):281-283.

Agusti, M.; Almela, V. (1991). Aplicacion de fitorreguladores en citricultura. Barcelona: Ed. Aedos. 262p.

Banzatto, D.A.; Kronka, S.N. (2006). Experimentação agrícola. $4^{\mathrm{a}}$ ed. Jaboticabal: FUNEP. 237p.

Castro, P.R.C.; Medina, C.L.; Pacheco, A.C. (1996). Potencialidade para a utilização de reguladores vegetais na citricultura brasileira. Laranja 17 (1): 109-121.
Castro, P.R.C.; Pacheco, A.C.; Medina, C.L. (1998). Efeitos de Stimulate e de Micro-Citros no desenvolvimento vegetativo e na produtividade de laranja 'Pêra' (Citrus sinensis L. Osbeck). Scientia Agrícola $\quad 55 \quad$ (2): 338341.http://dx.doi.org/10.1590/S010390161998000200026

Castro, P. R. C.; Vieira, E. L. (2001). Aplicação de reguladores vegetais na agricultura tropical. Guaíba: Livraria e Editora Agropecuária Ltda., $132 \mathrm{p}$.

Dantas, A. C. V. L; Queiroz, J. M. O.; Vieira, E. L.; Almeida, V. O. (2012). Influência do ácido giberélico e do bioestimulante Stimulate ${ }^{\circledR}$ no crescimento inicial de tamarindeiro. Revista Brasileira de Fruticultura 34 (1): 8-14. http://dx.doi.org/10.1590/S010029452012000100004.

Ercher. M. de M.; Guimarães, V. F.; Krieser, C.R.; Abucarma, V. M.; Klein, J.; Santos, L.; Dallabrida, W.R. (2006). Uso de bioestimulante na formação de 
mudas de maracujazeiro amarelo. Semina: Ciências Agrárias 27 (3): 351-360.

http://dx.doi.org/10.5433/1679-

0359.2006v27n3p351

Food and Agriculture Organization of the United Nations - FAO. (2016) Citrus Fruit Fresh and Processed: annual statistics 2012. Disponível em: http://www.fao.org/fileadmin/templates/est/COMM_ MARKETS_MONITORING/Citrus/

Documents/CITRUS_BULLETIN_2012.pdf. Acesso em: 30 jan 2017.

Ferrari, T. B.; Ferreira, G.; Zucareli, V.; Boara, C. S. F. (2008). Efeito de reguladores vegetais nos índices da análise de crescimento de plântulas de maracujazeiro-doce (Passiflora alata Curtis). Biotemas 21 (3): 45-51.

Ferreira, D. F. (2011). Sisvar: a computer statistical analysis system. Ciência e Agrotecnologia 35 (6): 1039-1042.

http://dx.doi.org/10.1590/S1413-70542011000600001

Glinski, D. S.; Karnok, K. J.; Carrow, R. N. (1993).Comparison of reporting methods for root growth data from transparent-interface measurements. Crop Science 33 (1): 310-314.

IAC (Centro de Citricultura Sylvio Moreira). O Agronômico - IAC na bioeconomia da citricultura brasileira. Boletim Técnico-Informativo do Instituto Agronômico - ISSN 0365 - 2726. 2016. Disponível em: < http://oagronomico.iac.sp.gov.br/?p=16 >. Acesso em: 21 ago. 2017.

Natale, W.; Prado, R. M.; Leal, R. M.; Franco, C. F. (2004). Efeitos da aplicação de zinco no desenvolvimento, no estado nutricional e na produção de matéria seca de mudas de maracujazeiro. Revista Brasileira de Fruticultura 26 (2): 310-314.

http://dx.doi.org/10.1590/S0100-

29452004000200031

Oliveira, F. D. A., Medeiros, J. F., Cunha, R. C., Souza, M. W. L., Lima, L. A. (2016). Uso de bioestimulante como agente amenizador do estresse salino na cultura do milho pipoca. Revista Ciência Agronômica 47 (2):307.
Queiroz, J.M.O. (2009). Propagação do tamarindeiro (Tamarindus indica L.). Cruz das Almas: Centro de Ciências Agrárias e Ambientais, Universidade Federal do Recôncavo da Bahia. 68 p. Dissertação (Mestrado em Ciências Agrárias).

Rezende, C. F. A.; Fernandes, E. P.; Silva, M. F.; Leandro, W.M. (2010) Crescimento e acúmulo de nutriente em mudas cítricas cultivadas em ambiente protegido. Bioscience Journal 26 (3):367-375.

Rodrigues, M. J. S.; Oliveira, E. R. M.; Girardi, E. A.; Silva, L. C. A.; Soares Filho, W. S. (2015) Fruit characterization and propagation of hybrid citrus rootstocks in protected environment. Revista Brasileira de Fruticultura 37 (2):457-470.

http://dx.doi.org/10.1590/0100-2945-068/14

Santos, C. M.; Vieira, E. L. (2005). Efeito de bioestimulante na germinação de sementes, vigor de plântulas e crescimento inicial do algodoeiro. Magistra 17 (3): 124-130.

Stoller do Brasil (1998). Stimulate Mo em hortaliças: Informativo técnico. Cosmópolis, Stoller do Brasil. 1p.

Souza, J. M. A.; Gonçalves, B. H. L.; Santos, A. M. F.; Ferraz, R. A.; Leonel, S. (2013). Efeito de bioestimulante no desenvolvimento inicial de plântulas do porta-enxerto cítrico tangerineira 'Cleópatra'. Scientia Plena 9 (8): 1-8.

Tecchio, M. A.; Leonel, S.; Reis, L.L.; Simonetti, L.M.; Silva, M. J. R. (2015). Stimulate no desenvolvimento de mudas de Kunquat 'nagami'. Irriga Edição Especial, 20 anos Irriga +50 anos FCA 97-106.

Toledo, M. Z.; Fachin, C. A.; Zucareli, V. (2015). Qualidade fisiológica de sementes esverdeadas de soja tratadas com bioestimulante. Revista de Agricultura 90 (1): 63-76.

Vendruscolo, E.P., Souza, H.B., Arruda, L.A., Lima, S.F., Alvarez, R.C.F. (2015). Biorregulador na germinação e desenvolvimento inicial do algodoeiro. Revista de Ciências Agro-ambientais 13 (2): 3240. 